\title{
REMOTE-SYNCHRONOUS SIMULATION OF AN EMERGENCY ROOM FOR MEDICAL STUDENTS
}

\author{
Hambleton $\mathrm{A}^{1^{*}}$ and Lopez $\mathrm{M}^{1,2}$ \\ ${ }^{I}$ Tecnologico de Monterrey, Escuela de Medicina y Ciencias de la Salud, Mexico \\ ${ }^{2}$ Writing Lab, Institute for the Future of Education, Tecnologico de Monterrey, \\ Monterrey, Mexico
}

\begin{abstract}
The pandemic's historical challenge has forced the international academic community to design new learning strategies, explore teaching methods, and develop skills through digital education. Particularly in medical education, early hands-on training is vital for the development of clinical skills. Remote simulations pose an innovative opportunity to encourage reflection on performance and transfer knowledge towards a demonstrable experience. The objective of this study was to develop and assess a remotesynchronous simulation experience. The study considered a quantitative approach with a descriptive and cross-sectional design. The sample consisted of 54 fourth-year medical students enrolled in a distance course on respiratory pathophysiology. The strategy was implemented through remote-synchronous simulations of 90 minutes using a videoconference platform. Students experienced the images, sounds, voices, and tension of an emergency room setting. The process considered 3 phases: 1)Design 2) Implementation 3)Reflective moment. To assess the experience, students were asked to participate in a survey with a 5-point Likert scale, where 5 depicts a more favorable response. Results show that students believe adapting to the remote-simulation was easy (3.92), and participating in the innovation was satisfactory for them (4.70). This remote-synchronous simulation of an emergency room for medical students provided a significant learning experience and a space for reflection that was highly valued for students. It is essential to highlight that it was easy to implement for the faculty members, and it was a low-cost alternative to offer early training experience amid the pandemic. This model may be transferable for other contexts and professions to enrich training in blended-learning formats.
\end{abstract}

Keywords: educational innovation, medical education, remote-simulation, pandemic adaptations, distance learning

\section{Introduction}

Clinical simulation scenarios allow the students to be placed in a learning environment to address targeted educational objectives by recreating realistic professional practice elements (Segura, ErañaRojas, Lopez, 2018). This strategy offers various advantages; the most evident is targeted skill development and reflecting on what has been learned, and building on previous knowledge (Valdez, Lopez, Barrientos, 2017). The opportunities of clinical simulation are countless, as this strategy has shown to favor the retention of knowledge, and in general, participants perceive simulation-based learning experiences as satisfactory (Padilha, 2019). An essential factor for this perception is for it to be tightly intertwined to assessment to provide feedback that informs practice and to document or 
measure the achievement of the educational objectives and competencies required for the medical profession (Dávila, 2014; Segura, Valencia \& López, 2019, Pei \& Wu, 2019).

These skills are of particular importance in care environments for critical patients or emergencies are scenarios where the skills are put to practice in a rapid and complex setting. In their first years of training, medical students have limited exposure to these deeply constructing moments. As they progress in their program, they progressively acquire more responsibility (Valdez, Lopez \& Barrientos, 2017). However, patient care still relies on the supervision and intervention by accredited and certified clinical personnel. The student still needs to be prepared for, when the time comes, assume the responsibility with competence and confidence (Segura, Eraña \& Lopez, 2018). Simulated scenarios provide exposure to what the challenge of emergency settings are, providing an adequate fast response.

Integrating technology and online learning into a simulation setting provides many benefits to make more efficient educational strategies (Mejía, Lopez, Hernandez-Rangel, Cerano, 2019; Ruiz-Parra, 2009). An added contribution is that it enables medical students' training and assessment despite the spread of COVID-19. Among some of the challenges that the pandemic has presented to the educational community in medicine is designing and implementing more flexible learning strategies. However, openness and prior educational innovation experiences might be the critical factor in facilitating technology incorporation (Lopez, Hernandez-Rangel \& Cerano, 2019). Some examples of the implementation of these educational innovations have been online video conferencing and discussion forums. These proposals need to leverage synchronous and asynchronous forms, including individual and collaborative work in small groups through technological platforms (Valdez, Lopez, Jimenez, Díaz, Dávila \& Olivares, 2020).

For doctors in training, having a menu of technologies and experiences for them to choose from is a way to encourage them to become participants and responsible for their learning. Those experiences' quality design could foster critical thinking to acquire and discriminate information, develop effective communication, collaborative work, and incorporation of information technologies (Herrera, 2015). As a result of the pandemic, these skills have taken a new virtual form which has provided a fuller menu of engaging digitizing educational environments (Méndez \& Lopez, 2020).

Some authors recommend the inclusion of flipped classrooms and favor active learning strategies to make the most of the time available for direct interactions (Ferrer \& Ryan 2020; Herrera \& Toro 2020). Given the unexpectedness of events and the speed with which educational institutions and their community had to migrate to digital models, inequalities and even lack of resources have become evident in educational communities from low-income countries. These inequalities due to the availability of infrastructure and materials to support virtual learning may impact education quality (Aguilar et. al, 2020). Therefore, teachers' creativity has focused on finding simple, low-cost, and easily scalable models to mitigate these deficiencies and foster engaging environments for learning (Méndez \& Lopez, 2020).

Amid the pandemic, medical schools and teaching hospitals have turned to simulation as a valuable learning tool (González-Urquijo et al., 2021). Some universities have focused these simulated experiences on training skills related to the care of patients with COVID-19; others have reached to telemedicine, where students can participate in a technology-mediated medical encounter (Harder, 
2020). To train students to care for a patient with respiratory failure in the emergency room, a virtual scenario including clinical simulation needed to be developed. This study's objective was to develop and assess a remote-synchronous simulation experience through the perception of the students who participated in the scenario.

\section{Methods}

This study considered a quantitative approach with a non-experimental, descriptive, and crosssectional design to assess the participating students' experience in a single moment after the implementation. The sample consisted of 54 fourth-year medical students enrolled in a distance course of respiratory physiopathology at a private university in northern Mexico. They were invited to participate voluntarily in a formative exercise during the August to December 2020 semester.

The instrument for collecting the participants' perceptions used a 5-point Likert scale, where 5 depicts a more favorable response. The selected questions were: How easy was it to adapt to a synchronous virtual simulation? and How satisfying was the experience of a synchronous virtual simulation?

The process of developing this simulation considered 3 phases: 1)Design 2)Implementation 3)Reflective moment (Figure 1)
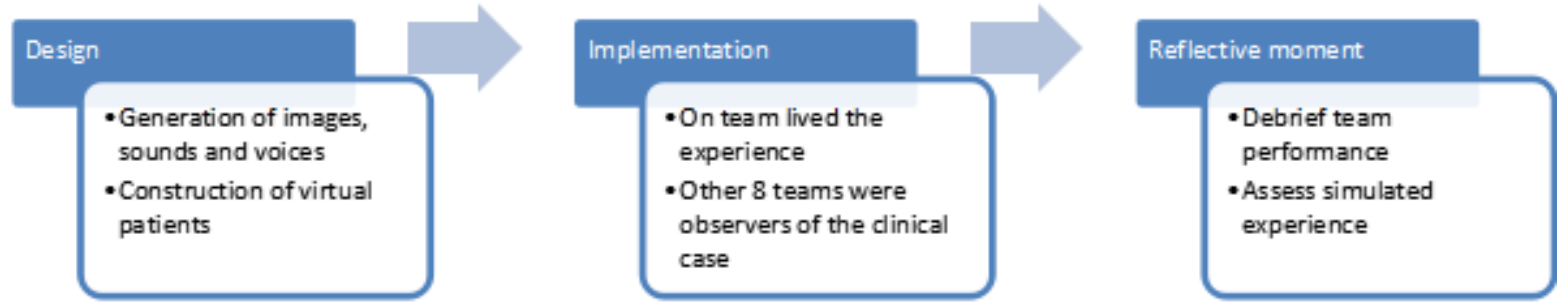

Fig.1: Development process of the simulated scenario for medical students

In the design phase, images, sounds, and voices were arranged in a way that would result in each of the simulated patients in acute respiratory failure. In the implementation phase, the simulated scenarios were resolved so that each team could once be responsible and be observers in the rest of the scenarios. In the reflexive moment phase, debriefing and assess the experience students were asked to answer the instrument.

The strategy for conducting the study consisted of remote-synchronous simulation events of respiratory failure patient-cases, during 90 minutes, using a videoconference platform, through which the participants experienced the images, sounds, voices, and tension or an emergency room setting, designed by a tutor for the exercise. The 54 students were randomly assigned into nine groups that participated in one of the three different scenarios (table 1). These experiences were designed to be 30 minutes long, so the students could participate in the experience live during the class session.

Table 1: Description of patient's cases

\begin{tabular}{lll}
\hline Scenario & Patient & Description \\
\hline Case 1 & 3 years old, male & $\begin{array}{l}\text { Presented to the emergency room with 3 hours of tachypnea, } \\
\text { stridor, and fever }\end{array}$ \\
\hline Case 2 & 7 years old, male & $\begin{array}{l}\text { Presented to the emergency room with 3 hours of wheezing, } \\
\text { tachypnea, and fever }\end{array}$ \\
\hline
\end{tabular}




\section{Results}

Of the 54 participating students, 33 were women and 21 men. Overall, the participants perceived it was easy to adapt to a remote simulation (3.92) and seem satisfied with the experience (4.70). As seen in Table 2, the participant's perception of how well they adapted to the remote simulated experience was 3.75 for the ones in case 1, 3.94 for the ones in case 2, and 4.05 for the ones in case 3 . The results for satisfaction with the implementation of the strategy had a mean of 4.72 for the ones in case 1, 4.66 for the ones in case 2, and 4.72 for the ones in case 3.

Table 2: Students perception of the experience

\begin{tabular}{lll}
\hline Scenario & $\begin{array}{l}\text { How easy was it to adapt to } \\
\text { synchronous virtual } \\
\text { simulation? }\end{array}$ & $\begin{array}{l}\text { How satisfying was the experience } \\
\text { of synchronous virtual simulation? }\end{array}$ \\
\hline Groups that participated in case 1 & 3.75 & 4.72 \\
\hline Groups that participated in case 2 & 3.94 & 4.66 \\
\hline Groups that participated in case 3 & 4.05 & 4.72 \\
\hline Overall perception & 3.92 & 4.70 \\
\hline
\end{tabular}

Case 1 focused on a 3-year-old patient that presented to the emergency room with 3 hours of tachypnea, stridor, and fever which may be complicated for students as stridor is an abnormal breath sound that may be confused with wheezing in the sounds simulator, so the students need to be a focus in the physical exam. In a remote scenario, where they could not touch the patient, these skills are more difficult for them. In the implemented innovation, students hear pre-recorded sounds from a simulator of respiratory noises. The sounds emitted from stridor and wheezing have a high-pitched whistling tone because of their origin in the narrow respiratory conducts. Given the impossibility of a complete physical examination, it was difficult for them to perceive the difference between them through their headphones. Some students used the computer speakers, and others had access to specialized audio equipment that facilitated the experience, but technology might have influenced their possibility of emitting a diagnosis.

Case 2 focused on a 7-year-old patient who presented to the emergency room with 3 hours of wheezing, tachypnea, and fever which was a more straightforward case to interact with because patients from this age provide more interaction with the health provider. Students were able to ask the patient through structured approaches for patient history; they also gather valuable information regarding possible causes of the disease's mechanism, which students were able to connect to the theory that they have analyzed in class.

Case 3 focused on an 18 months patient who presented to the emergency room with tachypnea, fever, and bilateral rales, Th scenario was the least complicated from the clinical point of view, and the respiratory sounds that were used were easy to distinguish between a healthy and one with a pathology. 
No significant differences were found by gender in terms of ease of adapting to virtual simulation; however, the possibility is opened to explore whether differences in satisfaction have to do with gender perceptions or are related to the feeling of inexperience and anxiety that in other studies has been evidenced, with greater prevalence in the female sex.

\section{Discussion}

This remote-synchronous simulation of an emergency room for medical students provided a significant learning experience and a space for reflection that was highly valued for students. In these pandemic conditions, it promotes learning, allows skills development not to stop, and offers the opportunity to train future professionals to identify signs and alarm symptoms. The apparent differences in the perception of the experience across the different groups rely on the relatedness they had with identifying abnormal pulmonary sounds during the physical exam and the clarity of current disease mechanisms in each patient. Other studies have found similar results; when students face their first encounters with simulated patients, inexperience and anxiety might play a role in the scenario (Segura, Valencia \& López, 2019). Other factors particulars in the experience included sounds; the apparent difference in simulator sounds between wheezing and stridor is less evident so that identification is more complicated and causes the examiner feeling of helplessness.

One of the competencies necessary to carry out this synchronous simulation exercise is effective communication with patients, family members, and the rest of the health personnel. Other competencies are critical thinking about the data obtained during the interrogation, remote examination, and analysis of the data reflected on the monitor, as students could generate a diagnostic and initiate a therapeutic plan. During moments where interaction and feedback happened, students reflected and put into practice self-regulation. Although the intervention might be brief, it allows them to get closer to identifying elements of professionalism.

When educators generate virtual simulated environments, which synchronously allow students to experience similar experiences in presence-based simulation centers, the design and implementation of the simulation intervention in the emergency room studied have allowed them to perceive the tool as valuable, adaptable, and satisfactory. It is essential to highlight that this alternative was relatively easy to implement for faculty members, who have previously been trained in face-to-face, and it was a low-cost alternative to offer early training experience amid the pandemic. This model may be reproducible for other contexts and professions, considering that simulation offers fragments of the reality associated with professional life.

Clinical simulation has been developed due to advances in technology that have allowed us to replicate reality aspects in a controlled and safe way (Avila et al., 2016). Technology sums in virtuality, the opportunity to students learning focused on practice and synchronous reflection, guided by expert tutors. The elements used to recreate the scenarios have allowed the students to continue their learning amid the pandemic. The images, sounds, and voices of simulated patients and relatives, who have interacted with the students through the technological platform and synchronously, have allowed them to feel immersed in an environment close to an emergency department. By feeling in that place, they can experience first-hand the anxiety and importance of offering timely solutions to problems. These problems focused on making relevant decisions for the simulated patient's care in respiratory failure for the participants. The process has favored reflection and interaction with other 
team members, allowing observing students learn from the responsible care group's simulation performance.

The limitations of the results of the study are the size of the sample and the possibility of making a single intervention with the satisfaction measurement instrument, considering the possibility of expanding the analysis in future research, adding to the assessment of the perception of students, a qualitative analysis, through a group of approaches. Other limitations rely on the fact that it was conducted in a single institution in one country. Although it might seem like a small implementation, it is essential to notice that it was a pilot innovation when nothing was written. Medical education relied heavily on face-to-face settings, where contact with patients or actors representing patients was crucial to developing clinical skills related to patient care. As the mandatory or voluntary quarantine has prolonged, the research time was to expand this project. We are in the process of developing more cases and including more actors that could enrich the clinical presentation of the cases. The process needs to build on the assessment and feedback experience for students to benefit from it.

Future implementations can focus on the readiness for future learning, which in healthcare is an invaluable skill in which is a life-long learner can generate new strategies for development. An important lesson learned during the pandemic by both students and teachers to continue growing both professionally and personally. This educational innovation can be the starting point for novel learning strategies and studies to monitor the students who started their clinical training during the health crisis.

Measuring how effective the transition to an online learning experience was in medical students and how it might translate to future professional practice remains a challenge for educational researchers. It is known that different factors can affect this transition process, access to technology, stability in connectivity, selection of environmental-related material to recreate the reality elements of an emergency room, the experience, and arrangement of tutors, the fictional contract between the participants of the simulated scenario, the design of the scenario itself among others. However, these digital education models' advantages to develop skills have been a highlight (Pei \& Wu, 2019). Distance instruction has driven how students participate in the creation of their learning, and tutors have migrated from the chair to accompaniment in the development of competencies in the last two decades; likewise, teachers have incorporated advances in technology to monitor student progress, recreating simulation environment that is getting closer to professional reality.

\section{Conclusion}

The COVID-19 pandemic has brought the need to favor the development of students' skills through increased technology use in education. Due to the limitations that video conferencing tools or learning management systems may have if contrasted with face-to-face interaction, teachers have enhanced their creativity and engagement (Perron et al., 2020). The possibility of developing the skills in learners refers to fulfilling a promise to a client and a commitment towards the community to offer the best care possible. The new coronavirus has presented a time where health teams need to function like clockwork in an emergency room overflowing with infected patients; the least that medical schools can do is prepare the next generation of physicians to be ready to perform. Clinical simulation provides this opportunity to prepare undergraduate students, medical postgraduates, and specialists in distance or blended-learning models besides the pandemic. 


\section{Acknowledgments}

The authors would like to acknowledge the financial support of Writing Lab, TecLabs, Tecnologico de Monterrey, Mexico, in the production of this work.

\section{References}

Alfonso Sánchez, I. R. (2003). La educación a distancia. ACIMED, 11(1), 3-4.

Dávila A. (2014). Simulación en educación médica. Investigación en educación médica, 3(10), 100105.

Ávila, R., Mahana, P., Rivera, \& Mc Coll, P. (2016). Simulación Clínica como método de formación de competencias en estudiantes de medicina. Rev Educ Cienc Salud, 13(1), 11-14.

Ferrel, M. N. \& Ryan, J.J. (2020). The Impact of COVID-19 on Medical Education. Cureus. doi:10.7759/cureus.7492

González-Urquijo, M., Gonzalez-Hinojosa, D., Rojas-Mendez, J., \& Rodarte-Shade, M. (2021). Transferring face-to-face sessions to virtual sessions in surgical education: a survey-based assessment of a single academic general surgery program. European Surgery. https://doi.org/10.1007/s10353-021$\underline{00691-2}$

Harder, N. (2020). Simulation Amid the COVID-19 Pandemic. Clinical simulation in nursing, 43, 12. doi:10.1016/j.ecns.2020.03.010

Herrera, P., Cea, A., Cortés, M. T., Aburto, M. B., Farfán, A., \& Petra, I. (2015). Desafíos en la aplicación de las competencias en los años preclínicos de medicina. FEM: Revista de la Fundación Educación Médica, 18(3), 189-196.

Herrera-Añazco, P. \& Toro-Huamanchumo, C. J. (2020). Educación médica durante la pandemia delEducación médica durante la pandemia del COVID -19: iniciativas mundiales para el pregrado, internado y el residentado médico COVID -19: iniciativas mundiales para el pregrado, internado y el residentado médico. ACTA MEDICA PERUANA, 37 (2). doi:10.35663/amp.2020.372.999

Junod Perron, N., Dominicé Dao, M., Rieder, A., Sommer, J. \& Audétat, M.-C. (2020). Online Synchronous Clinical Communication Training During the Covid-19 Pandemic. Advances in medical education and practice, 11, 1029-1036. doi:10.2147/amep.s286552

Lopez, M., Hernández-Rangel, E., Mejía, G.P., \& Cerano, J.L. (2019). Factores que facilitan la adopción de tecnología educative en escuelas de medicina. Educación Médica, 20(1), 3-9.

Mejía, G.P., Lopez, M., Hernandez-Rangel, E., \& Cerano, J.L. (2019). Diseño de un modelo de evaluación mediante la integración de tecnología inmersiva y a distancia. Educación médica, 20(3), 140-145.

Méndez, A., \& Lopez, M. (2020). Coronabunker: let's just not talk about 'it'. Medical Education, 54(11), 1053-1054.

Padilha, J.M., Machado, P.P., Ribeiro, A., Ramos, J., \& Costa, P. (2019). Clinical Virtual Simulation in Nursing Education: Randomized Controlled Trial. J Med Internet Res, 21(3), e11529.

Pei, L., \& Wu, H. (2019). Does online learning work better than offline learning in undergraduate medical education? A systematic review and meta-analysis. Medical education online, 24(1), 1666538 .

Ruiz-Parra, A. I., Ángel-Muller, E., \& Guevara, Ó. (2009). La simulación clínica y el aprendizaje virtual. Tecnologías complementarias para la educación médica. Revista de la Facultad de Medicina, 57(1), 67-79.

Segura, N., Valencia, J., \& López, M. (2019). Desarrollo del pensamiento crítico mediante simulación de alta fidelidad en estudiantes de medicina. Investigación en Educación Médica, 7(28), 55-63. 
Segura, N.A., Eraña-Rojas, I.E., \& Lopez, M. (2018). High-fidelity simulation in pathophysiology courses with medical students. Educación Médica, 19(6), 355-358.

Valdez, J.E., Lopez, M., Jiménez, M.A., Díaz, J.A., Dávila, J.A., \& Olivares, S. (2020). Me preparo para ayudar: respuesta de escuelas de medicina y ciencias de la salud ante COVID-19. Investigación en Educación médica, 9(35), 85-95.

Valdez, J.E., Lopez, M., \& Ríos, E. (2017). Principles of assessment and effective feedback. Ann Eye Sci, 2(42), 1-10. doi: 10.21037/aes.2017.06.10

Weyrich, P., Schrauth, M., Kraus, B., Habermehl, D., Netzhammer, N., Zipfel, S., Jünger, J., Riessen, R., \& Nikendei, C. (2008). Undergraduate technical skills training guided by student tutors - Analysis of tutors' attitudes, tutees' acceptance and learning progress in an innovative teaching model. BMC medical education, 8 (1), s. 18. doi:10.1186/1472-6920-8-18 